\title{
The Canadian C-Spine Rule versus the NEXUS Low-Risk Criteria in Patients with Trauma
}

\author{
Ian G. Stiell, M.D., M.Sc., Catherine M. Clement, R.N., \\ R. Douglas McKnight, M.D., Robert Brison, M.D., M.P.H., \\ Michael J. Schull, M.D., M.Sc., Brian H. Rowe, M.D., M.Sc., \\ James R. Worthington, M.B., B.S., Mary A. Eisenhauer, M.D., Daniel Cass, M.D., \\ Gary Greenberg, M.D., Iain MacPhail, M.D., M.H.Sc., Jonathan Dreyer, M.D., \\ Jacques S. Lee, M.D., Glen Bandiera, M.D., Mark Reardon, M.D., \\ Brian Holroyd, M.D., Howard Lesiuk, M.D., and George A. Wells, Ph.D.
}

ABSTRACT

From the Departments of Emergency Medicine (I.G.S., J.R.W., G.G., M.R.) and Epidemiology and Community Medicine (G.A.W.), the Clinical Epidemiology Program (C.M.C.), and the Division of Neurosurgery (H.L.), University of Ottawa, Ottawa, Ont.; the Division of Emergency Medicine, University of British Columbia, Vancouver (R.D.M., I.M.); the Department of Emergency Medicine, Queens University, Kingston, Ont. (R.B.); the Division of Emergency Medicine, University of Toronto Toronto (M.J.S., D.C., J.S.L., G.B.); the Division of Emergency Medicine, University of Alberta, Edmonton (B.H.R., B.H.); and the Division of Emergency Medicine, University of Western Ontario, London (M.A.E., J.D.) - all in Canada. Address reprint requests to Dr. Stiell at the Clinical Epidemiology Unit, F657, Ottawa Health Research Institute, 1053 Carling Ave., Ottawa, ON KIY 4E9, Canada.

N Engl J Med 2003;349:2510-8.

Copyright @ 2003 Massachusetts Medical Society.
BACK GROU N D

The Canadian C-Spine (cervical-spine) Rule (CCR) and the National Emergency X-Radiography Utilization Study (NEXUS) Low-Risk Criteria (NLC) are decision rules to guide the use of cervical-spine radiography in patients with trauma. It is unclear how the two decision rules compare in terms of clinical performance.

\section{METHODS}

We conducted a prospective cohort study in nine Canadian emergency departments comparing the CCR and NLC as applied to alert patients with trauma who were in stable condition. The CCR and NLC were interpreted by 394 physicians for patients before radiography.

RESULTS

Among the 8283 patients, 169 (2.0 percent) had clinically important cervical-spine injuries. In 845 (10.2 percent) of the patients, physicians did not evaluate range of motion as required by the CCR algorithm. In analyses that excluded these indeterminate cases, the CCR was more sensitive than the NLC (99.4 percent vs. 90.7 percent, $\mathrm{P}<0.001)$ and more specific (45.1 percent vs. 36.8 percent, $\mathrm{P}<0.001$ ) for injury, and its use would have resulted in lower radiography rates $(55.9$ percent vs. 66.6 percent, $\mathrm{P}<0.001)$. In secondary analyses that included all patients, the sensitivity and specificity of CCR, assuming that the indeterminate cases were all positive, were 99.4 percent and 40.4 percent, respectively ( $\mathrm{P}<0.001$ for both comparisons with the NLC). Assuming that the CCR was negative for all indeterminate cases, these rates were 95.3 percent $(\mathrm{P}=0.09$ for the comparison with the NLC) and 50.7 percent $(\mathrm{P}=0.001)$. The $\mathrm{CCR}$ would have missed $1 \mathrm{pa}-$ tient and the NLC would have missed 16 patients with important injuries.

CONCLUSIONS

For alert patients with trauma who are in stable condition, the CCR is superior to the NLC with respect to sensitivity and specificity for cervical-spine injury, and its use would result in reduced rates of radiography. 
$\mathrm{E}$ MERGENCY DEPARTMENTS IN THE United States and Canada annually treat more than 13 million patients with trauma who are at risk for cervical-spine injury. ${ }^{1}$ Very few of these patients have a cervical-spine fracture, and the current pattern of use of radiography is not efficient. $^{2-11}$ There is considerable variation in published guidelines and also among physicians with respect to the use of radiography. ${ }^{12-15}$ Cervical-spine radiography is a "little-ticket" item - a low-cost procedure that adds substantially to health care costs because of the high volume of its use. ${ }^{16,17}$ Furthermore, patients are often immobilized on a backboard for many hours while awaiting radiography, leading to considerable discomfort and unnecessary use of space in crowded emergency departments. ${ }^{18-20}$

A clinical-decision rule is derived from original research and is defined as a decision-making tool that incorporates three or more variables from the history, examination, or simple tests. ${ }^{21-25}$ Two decision rules have been developed independently to permit more selective ordering of cervical-spine radiography, more rapid ruling out of injury to the cervical spine for patients, and substantial health care savings. The National Emergency X-Radiography Utilization Study (NEXUS) Low-Risk Criteria (NLC) include five items (Table 1 ) and were first described in 1992. ${ }^{27,28}$ A subsequent validation study in the United States involving 34,069 patients with trauma showed that the NLC had a sensitivity of 99.6 percent and a specificity of 12.9 percent for cervicalspine injury. 26,29 This rule has been recommended for use by emergency department physicians. ${ }^{13,14}$

More recently, our group developed the Canadian C-Spine (cervical-spine) Rule (CCR), for use with alert patients in stable condition, by evaluating 8924 cases. ${ }^{30-32}$ This rule is based on three high-risk criteria, five low-risk criteria, and the ability of patients to rotate their necks (Fig. 1). The goal of the current study was to compare prospectively the accuracy, reliability, clinical acceptability, and potential effect of the CCR and the NLC in alert patients with trauma who were in stable condition - an important step before using a decision rule in actual patient care.

\section{METHODS}

\section{STUDY POPULATION}

This prospective cohort study was conducted in the emergency departments of nine Canadian tertiary care hospitals. (The hospitals that were the sites for this study are listed in the Appendix.) We considered for enrollment consecutive adults (defined as persons 16 years old or older) with acute trauma to the head or neck who were both in stable condition and alert and who had either neck pain or no neck pain but met all of the following criteria: they had visible injury above the clavicles, were nonambulatory, and who had a dangerous mechanism of injury. Additional eligibility criteria were a Glasgow Coma Scale score of 15 out of 15 ( 3 is the low end of the scale, and 15 indicates alert and oriented), normal vital signs as defined by the Revised Trauma Score (a combined score based on the Glasgow Coma Scale, systolic blood pressure, and respiratory rate), ${ }^{12}$ and injury within the previous 48 hours. Patients were ineligible if they were under the age of 16 years; had penetrating neck trauma, acute paralysis, or known vertebral disease; had been evaluated previously for the same injury; or were pregnant. The research ethics board at each participating institution approved the study and waived the requirement for written informed consent.

\begin{tabular}{|l}
\hline Table 1. The NEXUS Low-Risk Criteria.* \\
\hline Cervical-spine radiography is indicated for patients with trauma unless they \\
meet all of the following criteria: \\
No posterior midline cervical-spine tenderness, $\uparrow$ \\
No evidence of intoxication, $\$$ \\
A normal level of alertness, $\llbracket$ \\
No focal neurologic deficit, $\emptyset$ and \\
No painful distracting injuries. $\|$
\end{tabular}

* Criteria are from Hoffman and colleagues. ${ }^{26}$

$\uparrow$ Midline posterior bony cervical-spine tenderness is present if the patient reports pain on palpation of the posterior midline neck from the nuchal ridge to the prominence of the first thoracic vertebra, or if the patient evinces pain with direct palpation of any cervical spinous process.

$\downarrow$ Patients should be considered intoxicated if they have either of the following: a recent history provided by the patient or an observer of intoxication or intoxicating ingestion, or evidence of intoxication on physical examination such as an odor of alcohol, slurred speech, ataxia, dysmetria, or other cerebellar findings, or any behavior consistent with intoxication. Patients may also be considered to be intoxicated if tests of bodily secretions are positive for alcohol or drugs that affect the level of alertness.

$\int$ An altered level of alertness can include any of the following: a Glasgow Coma Scale score of 14 or less; disorientation to person, place, time, or events; an inability to remember three objects at five minutes; a delayed or inappropriate response to external stimuli; or other findings.

9A focal neurologic deficit is any focal neurologic finding on motor or sensory examination.

\| No precise definition of a painful distracting injury is possible. This category includes any condition thought by the clinician to be producing pain sufficient to distract the patient from a second (neck) injury. Such injuries may include, but are not limited to, any long-bone fracture; a visceral injury requiring surgical consultation; a large laceration, degloving injury, or crush injury; large burns; or any other injury causing acute functional impairment. Physicians may also classify any injury as distracting if it is thought to have the potential to impair the patient's ability to appreciate other injuries. 


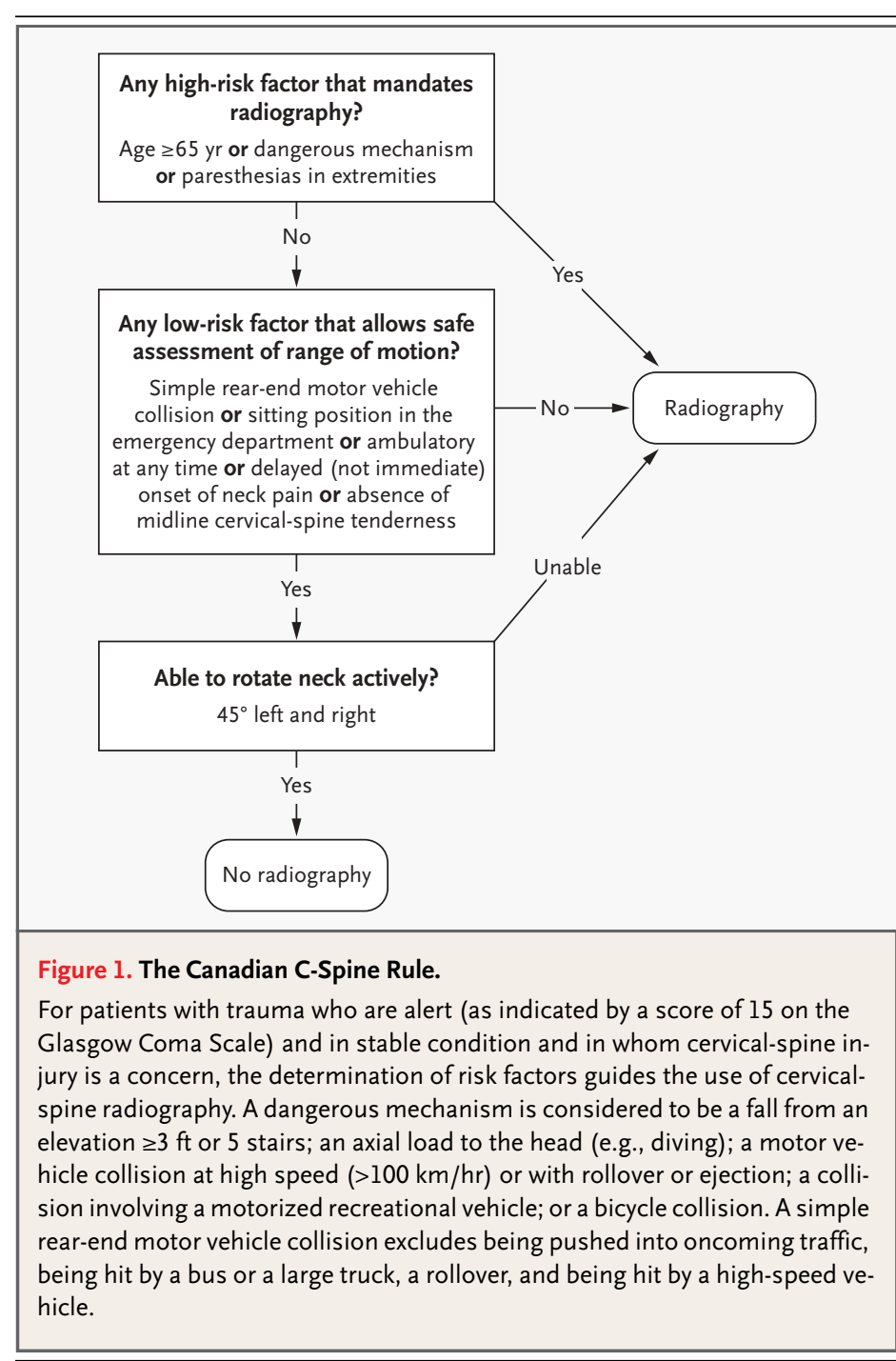

\section{ASSESSMENTS}

All assessments of the patients were made by attending or resident emergency medicine physicians, who were trained by means of a one-hour lecture session that did not involve testing of knowledge. After assessment and before radiography, the physicians recorded their findings and interpretations of the rules on data forms. The wording of the NLC was finalized with consultation and approval from the NEXUS investigators (Table 1). ${ }^{26}$ When feasible, some patients were assessed independently by a second emergency medicine physician, and interobserver agreement was determined.

\section{OUTCOME MEASURES}

The primary outcome, clinically important cervicalspine injury, was defined a priori as any fracture, dis- location, or ligamentous instability demonstrated by imaging. All injuries were considered clinically important unless radiography demonstrated one of the following isolated clinically unimportant fractures: osteophyte avulsion, a transverse process not involving a facet joint, a spinous process not involving lamina, or simple vertebral compression of less than 25 percent of body height. This definition had been standardized previously on the basis of a formal survey of 129 spine surgeons, neuroradiologists, and emergency physicians. ${ }^{33}$ Patients underwent standard plain radiography according to the judgment of the treating physicians, who were cautioned not to order radiography according to the decision rules. Radiographs were interpreted by staff radiologists who were provided with routine clinical information but not the contents of the data forms. Additional views and investigations were ordered at the discretion of the treating physician. All patients with an identified injury underwent computed tomographic (CT) scanning.

We could not request radiography for all patients, since the practice at the study hospitals was that only 70 percent of eligible patients (those who met the study criteria) routinely underwent cervicalspine imaging. Consequently, patients who did not undergo radiography were evaluated with the use of the Proxy Outcome Assessment Tool. A study nurse contacted these patients by telephone and classified them as having no cervical-spine injury if they met all four of the following criteria at 14 days: mild neck pain or none, mild neck-movement restriction or none, neck collar not used, and a return to usual occupational activities. Patients who did not fulfill these criteria were recalled for cervical-spine radiography. The validity of these criteria to rule out acute cervical-spine injury had previously been determined by having the questionnaire applied to a random sample of patients in a derivation study who had all undergone radiography. ${ }^{34}$ The criteria were 100 percent sensitive for identifying 66 cases of cervical-spine injury among 389 patients.

\section{STATISTICAL ANALYSIS}

The performance of the two rules in classifying patients according to whether or not they had acute cervical-spine injury was assessed for sensitivity and specificity. The final interpretation of the rules (i.e., whether the outcome was positive or negative for injury) was made by an adjudication committee, which reviewed the patients' medical records and the physicians' responses to the data forms. Interobserver agreement for each variable and for interpretation of 
the rules was measured with the kappa coefficient. All reported P values are two-tailed. Proportions were compared between the CCR and NLC by means of unadjusted chi-square analysis. We estimated that a sample of 8000 patients would be required to yield 120 cases of clinically important injury.

\section{RESULTS}

From May 1999 to April 2002, 8283 eligible patients were enrolled and had complete outcome assessments; an additional 3603 eligible patients were not enrolled by the physicians, and another 635 had data forms but no outcome assessments. A total of 394 physicians participated. Tables 2 and 3 show the characteristics of the study patients; 169 (2.0 percent) had clinically important cervical-spine injuries, all of which were identified in the emergency department without the use of the Proxy Outcome Assessment Tool. The characteristics of the eligible patients who were not enrolled were almost identical to those of the enrolled patients. The characteristics of the 635 patients without outcome assessments were similar to those of the enrolled subjects, but this group did not undergo radiography.

In 845 patients (10.2 percent), physicians did not

\begin{tabular}{|c|c|c|c|}
\hline Characteristic & Value & Characteristic & Value \\
\hline Age $-y r$ & & Characteristics of motor vehicle collision - no. (\%) & \\
\hline Mean & $37.6 \pm 16$ & Simple rear-end collision & $1812(21.9)$ \\
\hline Range & $16-100$ & Ejection from vehicle & $68(0.8)$ \\
\hline Male sex — no. (\%) & $4328(52.3)$ & Rollover & $444(5.4)$ \\
\hline Mechanism of injury - no. (\%) & & Death of other(s) in same collision & $42(0.5)$ \\
\hline Motor vehicle collision & $5564(67.2)$ & Head-on collision & $263(3.2)$ \\
\hline Motorcycle collision & $78(0.9)$ & Time from injury to assessment (hr) & $4.1 \pm 16.2$ \\
\hline Collision involving other motorized vehicles & $53(0.6)$ & Arrived at hospital by ambulance - no. (\%) & $5210(62.9)$ \\
\hline Pedestrian struck and thrown & $107(1.3)$ & Transferred from another institution - no. (\%) & $476(5.7)$ \\
\hline Pedestrian struck & $158(1.9)$ & Cervical-spine radiography performed — no. (\%) & $5936(71.7)$ \\
\hline Bicycle struck & $96(1.2)$ & Telephone follow-up required - no. (\%) & $2338(28.2)$ \\
\hline Bicycle collision & $61(0.7)$ & Acute cervical-spine injury — no. (\%) & $217(2.6)$ \\
\hline Other bicycle accident & $105(1.3)$ & Fracture & $209(2.5)$ \\
\hline Fall from elevation $>10 \mathrm{ft}(3 \mathrm{~m})$ or down $>15$ stairs & $183(2.2)$ & Dislocation & $71(0.9)$ \\
\hline $\begin{array}{l}\text { Fall from elevation of } 3 \text { to } 10 \mathrm{ft} \text { ( } 1 \text { to } 3 \mathrm{~m} \text { ) or down } \\
5 \text { to } 15 \text { stairs }\end{array}$ & $350(4.2)$ & Ligamentous instability & $8(0.1)$ \\
\hline Fall from elevation $<3 \mathrm{ft}(1 \mathrm{~m})$ or down $<5$ stairs & $641(7.7)$ & "Clinically important" cervical-spine injury — no. (\%) $\uparrow$ & $169(2.0)$ \\
\hline Assault with a blunt object & $73(0.9)$ & Development of neurologic deficit — no. (\%) & $45(0.5)$ \\
\hline Assault with fist or feet & $199(2.4)$ & Stabilizing treatments - no. (\%) & $180(2.2)$ \\
\hline Diving & $25(0.3)$ & Internal fixation & $44(0.5)$ \\
\hline Fall onto head (axial load) & $32(0.4)$ & Halo & $45(0.5)$ \\
\hline Contact sports (axial load) & $88(1.1)$ & Brace & $13(0.2)$ \\
\hline Heavy object onto head (axial load) & $74(0.9)$ & Rigid collar & $81(1.0)$ \\
\hline Other sports & $166(2.0)$ & Admitted to hospital — no. (\%) & $430(5.2)$ \\
\hline Head struck by other object & $106(1.3)$ & & \\
\hline Hit head on an object & $101(1.2)$ & & \\
\hline Other & $23(0.3)$ & & \\
\hline
\end{tabular}

* Plus-minus values are means $\pm S D$.

$\dagger$ "Clinically important" cervical-spine injury was defined as any injury except an isolated avulsion fracture of an osteophyte; an isolated fracture of a transverse process not involving a facet joint; an isolated fracture of a spinous process not involving lamina; and a simple compression fracture with less than 25 percent loss of vertebral body height. All clinically important injuries were detected at the initial visit to the emergency department. 


\begin{tabular}{|c|c|c|c|c|}
\hline \multicolumn{5}{|c|}{$\begin{array}{l}\text { Table 3. Univariate Correlation and Kappa Values for Individual Variables } \\
\text { in the NEXUS Low-Risk Criteria and the Canadian C-Spine Rule, According to } \\
\text { the Presence or Absence of Clinically Important Cervical-Spine Injury. }\end{array}$} \\
\hline \multirow[t]{2}{*}{ Findings* } & $\begin{array}{l}\text { Cervical- } \\
\text { Spine Injury } \\
(\mathrm{N}=169)\end{array}$ & $\begin{array}{l}\text { No Cervical- } \\
\text { Spine Injury } \\
(\mathrm{N}=8114)\end{array}$ & $P$ Value & $\begin{array}{c}\text { Kappa } \\
\text { Value } \\
(\mathrm{N}=142)\end{array}$ \\
\hline & \multicolumn{2}{|c|}{ percent } & & \\
\hline \multicolumn{5}{|l|}{ NEXUS Low-Risk Criteria } \\
\hline Midline neck tenderness $\dagger$ & 84.0 & 60.2 & $<0.001$ & 0.52 \\
\hline $\begin{array}{l}\text { Unreliable because } \\
\text { of intoxication }\end{array}$ & 10.1 & 4.1 & $<0.001$ & 0.72 \\
\hline $\begin{array}{l}\text { Motor or sensory deficit } \\
\text { in extremities }\end{array}$ & 12.4 & 3.4 & $<0.001$ & 0.64 \\
\hline Distracting painful injuries & 13.6 & 6.7 & 0.02 & 0.63 \\
\hline \multicolumn{5}{|l|}{ Canadian C-Spine Rule } \\
\hline Age 65 or older & 24.3 & 7.2 & $<0.001$ & NA \\
\hline Dangerous mechanism & 69.2 & 18.3 & $<0.001$ & NA \\
\hline Paresthesias in extremities & 22.5 & 12.2 & $<0.001$ & 0.81 \\
\hline $\begin{array}{l}\text { Simple rear-end motor } \\
\text { vehicle collisiont }\end{array}$ & 0 & 32.9 & $<0.001$ & 0.97 \\
\hline $\begin{array}{l}\text { Supine position during } \\
\text { examination }\end{array}$ & 94.1 & 65.4 & $<0.001$ & 0.70 \\
\hline Ambulatory at any time & 40.8 & 62.2 & $<0.001$ & 0.86 \\
\hline $\begin{array}{l}\text { Immediate onset of neck } \\
\text { pain }\end{array}$ & 81.4 & 61.8 & $<0.001$ & 0.74 \\
\hline Able to rotate neck & 7.7 & 55.9 & $<0.001$ & 0.49 \\
\hline \multicolumn{5}{|l|}{ Other findings } \\
\hline Posterior neck pain & 91.7 & 86.6 & 0.05 & 0.53 \\
\hline Visible facial or head injuries & 49.1 & 28.1 & $<0.001$ & 0.82 \\
\hline Able to flex neck & 4.1 & 51.6 & $<0.001$ & 0.45 \\
\hline
\end{tabular}

* The definitions of the variables are as follows: midline neck tenderness was defined as tenderness in a 2-cm-wide strip from the occiput to the level of $\mathrm{Tl}$; unreliable because of (suspected ethanol or drug) intoxication meant that the clinical assessment was judged to be unreliable because of the patient's condition; distracting painful injuries meant that there were other injuries, such as fractures, that were so severely painful that neck examination was unreliable ${ }^{27}$; able to rotate neck meant that the patient could turn left and right, to 45 degrees from midline, regardless of pain; and able to flex neck meant that the patient was able to touch chin to chest, if upright, or to lift the head $8 \mathrm{~cm}$ from the stretcher, if supine. NA denotes not assessed.

$\uparrow$ Midline neck tenderness is also among the criteria in the Canadian C-Spine Rule.

$\uparrow$ There were 1812 simple rear-end motor vehicle collisions out of a total of 5564 cases involving motor vehicle collisions. probably reflecting a cautious approach by physicians who were not comfortable testing range of motion in some cases. Seven of these 845 patients had clinically important cervical-spine injuries, and 4 were transferred with "presumed cervical-spine fracture."

The accuracy of the two rules is compared in Table 4 for 7438 cases, excluding the 845 indeterminate cases. The sensitivity of the CCR was 99.4 percent (95 percent confidence interval, 96 to 100), as compared with 90.7 percent ( 95 percent confidence interval, 85 to $94 ; \mathrm{P}<0.001$ ) for the NLC. The respective specificities were 45.1 percent $(95$ percent confidence interval, 44 to 46 ) and 36.8 percent ( 95 percent confidence interval, 36 to $38 ; \mathrm{P}<0.001)$. For 45 cases of clinically unimportant injuries, the sensitivity of the CCR was 97.8 percent, as compared with 80.0 percent for the NLC.

We performed secondary analyses involving all 8283 patients to determine the potential effect of indeterminate cases. When the CCR was assumed to be positive for all indeterminate cases, the sensitivity was 99.4 percent (95 percent confidence interval, 96 to 100), as compared with 90.5 percent (95 percent confidence interval, 85 to 94) for the NLC; the specificities were 40.4 percent ( 95 percent confidence interval, 39 to 42 ) and 33.0 percent ( 95 percent confidence interval, 33 to 35), respectively ( $\mathrm{P}<0.001$ for both comparisons). When the CCR was assumed to be negative for all indeterminate cases, the sensitivity was 95.3 percent ( 95 percent confidence interval, 91 to $97 ; \mathrm{P}=0.09$ ) and the specificity was 50.7 percent ( 95 percent confidence interval, 50 to $52 ; \mathrm{P}=0.001$ ).

Table 5 displays the characteristics of potentially missed cases. The single important case not identified by the CCR involved a man (Patient 4) who was injured in a motor vehicle collision but who could still walk and whose radiographs at the initial emergency department visit were normal. He returned one week later, CT scanning was performed, and he was found to have a type II odontoid fracture. The patient was assessed by a neurosurgeon, prescribed a hard collar, discharged directly home, and had no sequelae at a follow-up visit one year later. Of the other 15 cases not identified by the NLC, 14 met one or more CCR criteria and 1 was indeterminate.

The kappa value for interobserver agreement in the interpretation of the overall rules in 142 cases was 0.63 (95 percent confidence interval, 0.49 to 0.77) for the CCR and 0.47 (95 percent confidence interval, 0.28 to 0.65 ) for the NLC. A value greater 
than 0.60 is generally considered to reflect reasonable agreement.

Clinical acceptability was assessed in two ways. On a five-point Likert scale (ranging from "very uncomfortable" to "very comfortable"), physicians indicated that they would have been "uncomfortable" or "very uncomfortable" in applying the CCR in 8.0 percent of cases and in applying the NLC in 7.1 percent $(\mathrm{P}=0.03)$. Physicians misinterpreted the rules as not requiring radiography on the data forms, in contrast to the interpretation of the subsequent investigator that radiography was indicated, in $\mathbf{5 . 2}$ percent of cases evaluated with the use of the CCR (which could, theoretically, have led to 8 missed injuries) and 2.9 percent of those evaluated with the use of the NLC (which could have led to 14 missed injuries).

The potential effect on radiography was evaluated by estimating the proportion of patients who would require radiography according to the rules. For the CCR, the rate was 55.9 percent ( 95 percent confidence interval, 55 to 57), and for the NLC, 66.6 percent (95 percent confidence interval, 66 to 68 ; $\mathrm{P}<0.001)$. Secondary analyses that included the 845 indeterminate cases yielded potential radiography rates of 66.6 percent for the NLC, 50.2 percent if the indeterminate cases were considered to be negative according to the CCR, and 60.4 percent if the indeterminate cases were considered to be positive according to the CCR. The potential effect on crowding in the emergency department was assessed by determining the mean length of stay in the emergency department for patients without injury. The mean length of stay for the 4608 patients who underwent radiography was 232.9 minutes, as compared with 123.2 minutes for the 1997 patients who did not undergo radiography $(\mathrm{P}<0.001)$.

\section{DISCUSSION}

We found that the CCR was highly sensitive for clinically important cervical-spine injuries, identifying 161 of 162 cases in patients in whom the range of motion was evaluated. If the findings of the original derivation and current validation studies were combined, involving 16,363 patients, the CCR would have identified 312 of 313 clinically important cases, a sensitivity of 99.7 percent ( 95 percent confidence interval, 98 to 100). ${ }^{30}$ In contrast, the NLC had lower sensitivity than previously demonstrated, essentially missing 1 in 10 important injuries. Our results also showed the CCR to be more specific than the

\begin{tabular}{|c|c|c|c|c|}
\hline \multicolumn{5}{|c|}{$\begin{array}{l}\text { Table 4. Sensitivity, Specificity, and Negative Predictive Value of the Two Rules } \\
\text { for } 162 \text { Cases of "Clinically Important" Injury among } 7438 \text { Patients."* }\end{array}$} \\
\hline \multirow[t]{2}{*}{ Result of Assessment } & \multicolumn{2}{|c|}{ Canadian C-Spine Rule } & \multicolumn{2}{|c|}{ NEXUS Criteria } \\
\hline & Injury & No Injury & Injury & No Injury \\
\hline Positive (no.) & 161 & 3995 & 147 & 4599 \\
\hline Negative (no.) & 1 & 3281 & 15 & 2677 \\
\hline Sensitivity (\%) & \multicolumn{2}{|c|}{$99.4(95 \%$ Cl, 96-100)† } & \multicolumn{2}{|c|}{90.7 (95\% Cl, 85-94) † } \\
\hline Specificity (\%) & \multicolumn{2}{|c|}{$45.1(95 \%$ Cl, 44-46)† } & \multicolumn{2}{|c|}{$36.8(95 \% \mathrm{Cl}, 36-38) \dagger$} \\
\hline $\begin{array}{l}\text { Negative predictive value } \\
\text { (\%) }\end{array}$ & \multicolumn{2}{|l|}{100} & \multicolumn{2}{|l|}{99.4} \\
\hline \multicolumn{5}{|c|}{$\begin{array}{l}* \text { A total of } 845 \text { cases were classified as indeterminate and are therefore omitted } \\
\text { from this analysis. } \\
\uparrow \mathrm{P}<0.001 \text {. Cl denotes confidence interval. }\end{array}$} \\
\hline
\end{tabular}

NLC and, consequently, likely to have a greater effect in reducing unnecessary use of radiography and the need for immobilization. These findings raise questions about the safety and efficiency of applying the NLC in clinical practice.

The reliability of the physicians' interpretations appeared to favor the CCR over the NLC. However, physicians were slightly less comfortable and accurate using the CCR, and the potential effect of the CCR was diminished by the fact that range of motion was not always evaluated. We believe this happened primarily because some physicians were not always comfortable testing range of motion. For some physicians, this was a new procedure, and we note that the rate of indeterminate cases was highest during the first seven months of the study, reflecting an apparent learning curve. Secondary analyses incorporating indeterminate cases indicated that the CCR might have a lower sensitivity than suggested by the main analyses, although sensitivity still remained high, and specificity remained significantly higher than that of the NLC.

This prospective validation study was designed and conducted according to strict methodologic standards. ${ }^{21,22,35-37}$ The outcome, clinically important cervical-spine injury, was carefully defined and is of considerable clinical importance. Patients were selected according to strict criteria rather than on the basis of subjective decisions by physicians to order radiography. A large number of patients with injuries reflecting a wide spectrum of severity were enrolled, but children were excluded, because we believe that pediatric cases require distinct criteria. Also evaluated were other important measures in addition to accuracy, including interobserver agree- 


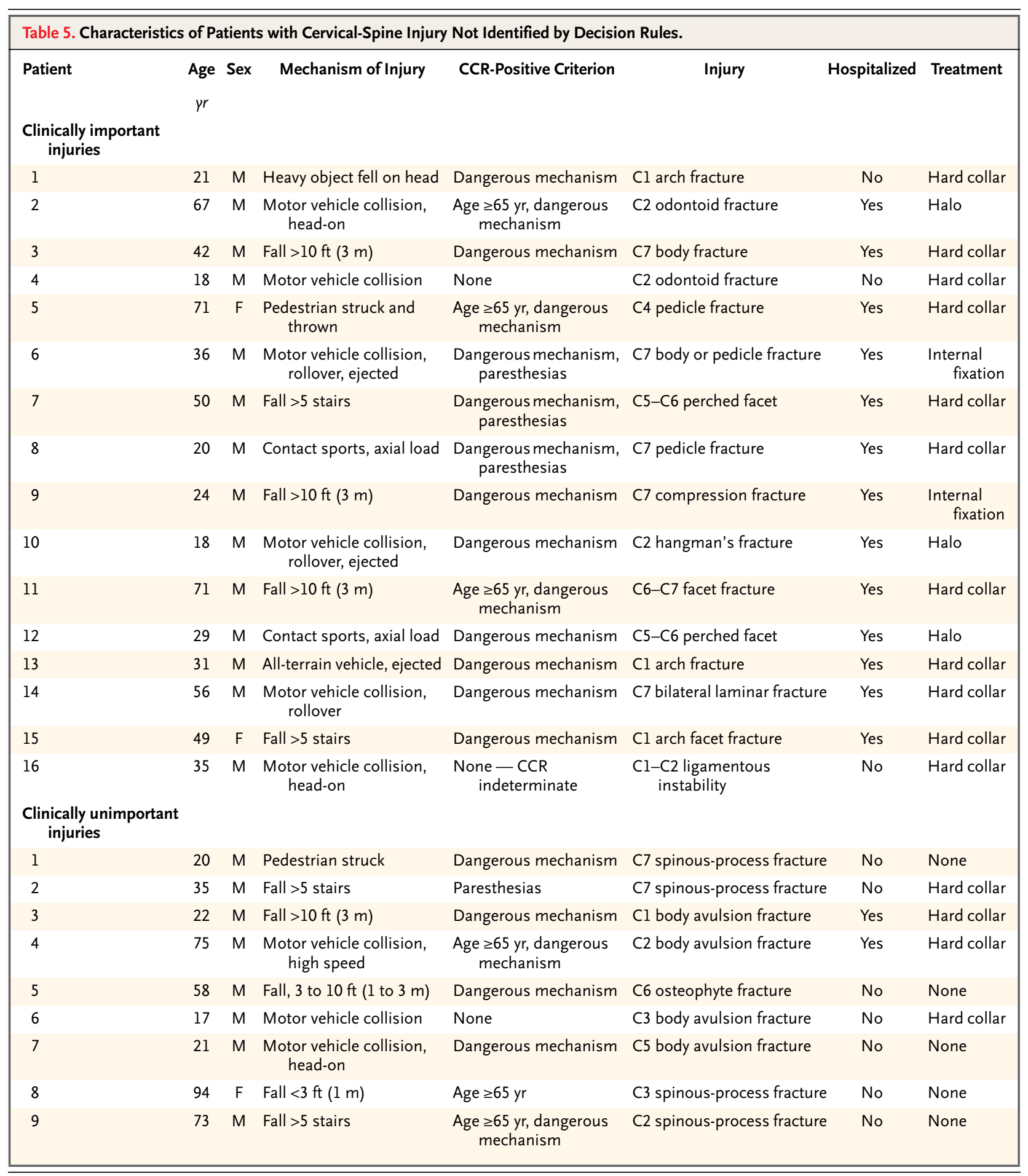

ment, clinical acceptability, and potential effect on practice.

This study has limitations, although most apply equally to both rules. Although not all eligible patients were enrolled, no selection bias could be de- tected, and the characteristics of enrolled and nonenrolled patients were similar. Some patients could not be reached for follow-up, but it is highly unlikely that any of these patients had a missed injury because none returned to the treating hospital or any 
other local neurosurgical center. A small proportion of patients had been transferred to the participating hospital, and it could be argued that physicians already knew that these patients had cervical-spine injury. However, less than 20 percent of transferred patients ultimately proved to have a cervical-spine injury.

Some may be concerned about the use of clinically important cervical-spine injury as the primary outcome, although it was applied equally to both rules. There has been very good acceptance of this definition by Canadian academic spine surgeons, neuroradiologists, and emergency department physicians, who consider it pragmatic and safe. Furthermore, the CCR was more sensitive than the NLC for clinically unimportant injuries.

Not all study patients underwent radiography, because the Canadian clinicians in the study often do not order imaging when they consider patients to be at low risk for spinal injury. Patients were classified as having "no important injury" only if they satisfied all criteria on the 14-day, Proxy Outcome Assessment Tool, which was conducted by telephone, has been validated, and was used equally for both rules.

Some cases were indeterminate on the CCR and could not be included in the primary analysis because the data forms did not include a physician's assessment of range of motion. Secondary analyses suggest that the study findings are robust except in the unlikely scenario that all indeterminate cases would have been classified as negative with the use of the CCR; in contrast, virtually all these patients were sent for radiography. Failure to assess range of motion in low-risk patients represents a cautious approach by some physicians, and this reluctance may be overcome by reassuring physicians that such an assessment is safe.

There was a slightly higher rate of misinterpretation for the CCR, which may reflect the fact that this rule is more complex. However, the misinterpretation rates were low for both rules.

There are several factors that may account for the current findings of lower sensitivity for the NLC than was reported earlier. ${ }^{26}$ First, the NLC were derived from a modest study of 27 cases of fracture among 974 patients and, when first reported in 1992, were based on only four criteria. ${ }^{27}$ The fifth, "no focal neurological deficit," was added at a later date without supporting evidence. The degree of interobserver agreement on the NLC variables was not evaluated until several years later. ${ }^{28}$ The data from the CCR derivation and validation studies raise questions about the accuracy and reproducibility of some NLC findings - namely "no distracting painful injuries," "no evidence of intoxication," and "no focal neurological deficit." 30

Second, the criteria for selecting patients were quite different in the NLC studies, which included infants and children, as well as patients with clouded consciousness and multiple trauma, and which enrolled only patients for whom radiography was ordered by a physician. There were no explicit inclusion and exclusion criteria that could be easily applied in other settings.

Third, the difference in the performance of the two rules should not be surprising, since the component clinical findings are quite different. One potential concern is whether the Canadian physicians, being more familiar with the CCR, could have unconsciously biased their responses to favor the $\mathrm{Ca}$ nadian rule. We believe this is unlikely. The NLC were accurately presented on the data forms after considerable discussion with the NEXUS investigators, although it remains possible that the Canadian physicians' interpretation of some of these criteria differed from that of their U.S. counterparts. Altered level of alertness was not assessed, since this was an explicit exclusion criterion. Furthermore, the responses for all cases were reviewed for accuracy by the adjudication committee. In particular, the 25 cases of clinically important or clinically unimportant injury that the NLC failed to identify were carefully reviewed, and the findings were determined to be accurate. These study results are very similar to those of a Canadian retrospective validation study that showed the NLC to have low sensitivity. 38

Our study confirmed the high sensitivity, reliability, and clinical acceptability of the CCR but failed to do so for the NLC. In some cases, physicians failed to evaluate range of motion as required by the CCR - an omission that, depending on how indeterminate results were handled, might slightly lower the sensitivity or specificity of the CCR in practice. Nevertheless, the CCR has the potential to standardize practice and improve efficiency in the use of cervical-spine radiography in most emergency departments. This could lead to substantial health care savings as well as reduced periods of immobilization in crowded emergency departments.

Supported by peer-reviewed grants from the Canadian Institutes of Health Research (MT-13700) and the Ontario Ministry of Health Emergency Health Services Committee (11996N). Dr. Stiell holds a Distinguished Investigator Award, Dr. Schull holds a New Investigator Award, and Dr. Rowe holds a Canada Research Chair, all from the Canadian Institutes of Health Research. 
We are indebted to Katherine Vandemheen and Andreas Laupacis for planning and assistance with earlier phases of the study; to study nurses Erica Battram, Kim Bradbury, Pamela Sheehan, Taryn MacKenzie, Kathy Bowes, Karen Code, Ann Zerdin, Virginia Blak-Genoway, Evelyn Gilkinson, Sharon Mason, Percy MacKerricher, Jan Buchanan, Jackie Miller, and Terry Shewchuk; to MyLinh Tran and
Emily Moen for data management; to Irene Harris for assistance in the preparation of the manuscript; to all the nurses and clerks at the study sites who assisted with case identification and data collection; and to the many staff physicians and residents who patiently completed thousands of data-collection forms and without whose voluntary assistance this study would not have been possible.

APPENDIX

The following hospitals participated in the study: Kingston General Hospital, Kingston, Ont.; Ottawa Hospital, Civic Campus, Ottawa, Ont.; Ottawa Hospital, General Campus, Ottawa, Ont.; Royal Columbian Hospital, New Westminster, B.C.; Sunnybrook and Women's College Health Sciences Centre, Toronto; Vancouver General Hospital, Vancouver, B.C.; University of Alberta Hospital, Edmonton, Alta.; St. Michael's Hospital, Toronto; and London Health Sciences Centre, Victoria Campus, London, Ont.

REFERENCES

1. McCaig LF, Ly N. National Hospital Ambulatory Medical Care Survey: 2000 emergency department summary. Advance data from vital and health statistics. No. 326 Hyattsville, Md.: National Center for Health Statistics, 2002. (DHHS publication no. (PHS) 2002-1250 02-0259.)

2. Reid DC, Henderson R, Saboe L, Miller JDR. Etiology and clinical course of missed spine fractures. J Trauma 1987;27:980-6.

3. Diliberti T, Lindsey RW. Evaluation of the cervical spine in the emergency setting: who does not need an X-ray? Orthopedics 1992;15:179-83.

4. Bachulis $\mathrm{BL}$, Long $\mathrm{WB}$, Hynes GD Johnson MC. Clinical indications for cervical spine radiographs in the traumatized patient. Am J Surg 1987;153:473-8.

5. Fischer RP. Cervical radiographic evaluation of alert patients following blunt trauma. Ann Emerg Med 1984;13:905-7.

6. Gbaanador GBM, Fruin AH, Taylon $\mathrm{C}$ Role of routine emergency cervical radiography in head trauma. Am J Surg 1986;152: 643-8.

7. Bayless P, Ray VG. Incidence of cervica spine injuries in association with blunt head trauma. Am J Emerg Med 1989;7:139-42.

8. Neifeld GL, Keene JG, Hevesy G, Leikin J, Proust A, Thisted RA. Cervical injury in head trauma. J Emerg Med 1988;6:203-7.

9. Vandemark RM. Radiology of the cervical spine in trauma patients: practice pitfall and recommendations for improving efficiency and communication. AJR Am J Roentgenol 1990;155:465-72.

10. Roberge RJ. Facilitating cervical spine radiography in blunt trauma. Emerg Med Clin North Am 1991;9:733-42.

11. Daffner RH. Cervical radiography in the emergency department: who, when, how extensive? J Emerg Med 1993;11:619-20.

12. Advanced trauma life support instructor manual. 6th ed. Chicago: American College of Surgeons, 1997.

13. Tintinalli JE, Kelen GD, Stapczynski JS. Emergency medicine: a comprehensive study guide. 5th ed. New York: McGraw-Hill, 1999.

14. Marx JA, ed. Rosen's emergency medicine: concepts and clinical practice. 5 th ed St. Louis: Mosby, 2002.

15. Stiell IG, Wells GA, Vandemheen K, et al. Variation in emergency department use of cervical spine radiography for alert, stable trauma patients. CMAJ 1997;156:1537-44. 16. Moloney TW, Rogers DE. Medical technology - a different view of the contentious debate over costs. N Engl J Med 1979;301: 1413-9.

17. Angell M. Cost containment and the physician. JAMA 1985;254:1203-7.

18. Schull MJ, Slaughter PM, Redelmeie DA. Urban emergency department overcrowding: defining the problem and eliminating misconceptions. Can J Emerg Med 2002;4:76-83.

19. Chan BT, Schull MJ, Schultz SE. Emergency department services in Ontario 1993 2000. Toronto: Institute for Clinical Evaluative Sciences, 2001.

20. Lindsay P, Bronskill S, Schull MJ, Chan BTB, Anderson GM. Clinical utilization and outcomes. In: Brown AD, ed. Hospital report 2001: emergency department care. Toronto: Ontario Hospital Association, 2001 29-47.

21. Laupacis A, Sekar N, Stiell JG. Clinica prediction rules: a review and suggested modifications of methodological standards. JAMA 1997;277:488-94

22. Stiell IG, Wells GA. Methodologic standards for the development of clinica decision rules in emergency medicine. Ann Emerg Med 1999;33:437-47.

23. Stiell IG, Greenberg GH, McKnight RD et al. Decision rules for the use of radiography in acute ankle injuries: refinement and prospective validation. JAMA 1993;269: 1127-32.

24. Stiell IG, Wells GA, Hoag RA, et al. Implementation of the Ottawa Knee Rule for the use of radiography in acute knee injuries. JAMA 1997;278:2075-9.

25. Stiell IG, Wells GA, Vandemheen K, et al. The Canadian CT Head Rule for patients with minor head injury. Lancet 2001;357: 1391-6.

26. Hoffman JR, Mower WR, Wolfson AB, Todd KH, Zucker MI. Validity of a set of clinical criteria to rule out injury to the cervical spine in patients with blunt trauma. $\mathrm{N}$ Engl J Med 2000;343:94-9. [Erratum, N Engl J Med 2001;344:464.]

27. Hoffman JR, Schriger DL, Mower W, Luo JS, Zucker M. Low-risk criteria for cervi- cal-spine radiography in blunt trauma: a prospective study. Ann Emerg Med 1992;21: 1454-60.

28. Mahadevan S, Mower WR, Hoffman JR, Peeples N, Goldberg W, Sonner R. Interrater reliability of cervical spine injury criteria in patients with blunt trauma. Ann Emerg Med 1998;31:197-201.

29. Hoffman JR, Wolfson AB, Todd $K$, Mower WR. Selective cervical spine radiography in blunt trauma: methodology of the National Emergency X-Radiography Utilization Study (NEXUS). Ann Emerg Med 1998; 32:461-9.

30. Stiell IG, Wells GA, Vandemheen K, et al. The Canadian C-Spine Rule for radiography in alert and stable trauma patients. JAMA 2001;286:1841-8.

31. Stiell IG, Wells GA, McKnight RD, et al Canadian C-Spine Rule study for alert and stable trauma patients. I. Background and rationale. Can J Emerg Med 2002;4:84-90.

32. Idem. Canadian C-Spine Rule study for alert and stable trauma patients. II. Study objectives and methodology. Can J Emerg Med 2002;4:185-93.

33. Stiell IG, Lesiuk HJ, Vandemheen K, et al. Obtaining consensus for a definition of "clinically important cervical spine injury" in the CCC Study. Acad Emerg Med 1999;6: 435. abstract.

34. Vandemheen K, Stiell IG, Brison R, et al. Validity evaluation of the cervical spine injury Proxy Outcome Assessment Tool in the CCC Study. Acad Emerg Med 1999;6:434. abstract.

35. Wasson JH, Sox HC, Neff RK, Goldman L. Clinical prediction rules: application and methodological standards. N Engl J Med 1985;313:793-9.

36. Feinstein AR. Clinimetrics. New Haven, Conn.: Yale University Press, 1987.

37. McGinn TG, Guyatt GH, Wyer PC, Naylor CD, Stiell IG, Richardson WS. Users' guides to the medical literature. XXII. How to use articles about clinical decision rules. JAMA 2000;284:79-84.

38. Dickinson G, Stiell IG, Schull M, et al. Retrospective application of the NEXUS low-risk criteria for cervical spine radiography in Canadian emergency departments. Ann Emerg Med (in press).

Copyright (c) 2003 Massachusetts Medical Society. 